\title{
Interactive comment on "A global monthly climatology of oceanic total dissolved inorganic carbon: a neural network approach" by Daniel Broullón et al.
}

\section{Daniel Broullón et al.}

daniel-bueu@hotmail.com

Received and published: 18 June 2020

We would like to thank referee \#2 for the comments to improve the manuscript. The answers and the new version of the manuscript can be seen in the attached pdf.

Daniel Broullón

Please also note the supplement to this comment: https://essd.copernicus.org/preprints/essd-2020-37/essd-2020-37-AC2supplement.pdf 
Interactive comment on Earth Syst. Sci. Data Discuss., https://doi.org/10.5194/essd-2020-37, 2020.

\section{ESSDD}

Interactive comment 